\title{
Postprandial hypotension in older adults: Can it be prevented by drinking water before the meal?
}

\author{
Bastien Grobéty ${ }^{1}$, Erik Konrad Grasser ${ }^{*}, 1$, Gayathri Yepuri, Abdul G. Dulloo, \\ Jean-Pierre Montani
}

Department of Medicine, Division of Physiology, Laboratory of Integrative Cardiovascular and Metabolic Physiology, University of Fribourg, 1700 Fribourg, Switzerland

\begin{abstract}
Background \& aims: An important consequence of ageing is a tendency for postprandial blood pressure to decline, which can lead to fainting. As a possible countermeasure, we investigated in healthy older adults the impact of drinking water before a breakfast meal on postprandial cardiovascular and autonomic functions.

Methods: After a stable cardiovascular baseline recording for at least $20 \mathrm{~min}$, twelve older adult $(67 \pm 1 \mathrm{y})$ test subjects ingested, in a crossover study design, either $100 \mathrm{~mL}$ or $500 \mathrm{~mL}$ of tap water over $4 \mathrm{~min}$, which was followed by the consumption of the test breakfast meal (1708 kJ) over a period of $15 \mathrm{~min}$. Then, cardiovascular recordings were resumed for 90 min after the meal. Eleven young ( $25 \pm 1 \mathrm{y}$ ) and healthy subjects served as a control group. Measurements included beat-to-beat blood pressure, heart rate, impedance cardiography and autonomic variables.

Results: In older adults, systolic and diastolic blood pressure started to decline around $30 \mathrm{~min}$ after the meal, with the lowest values around $60 \mathrm{~min}$; these effects were not observed in the young control group. Postprandial systolic blood pressure decreased between 30 and $90 \mathrm{~min}$ to a greater extent in response to $100 \mathrm{~mL}$ than to $500 \mathrm{~mL}$ ( -6.4 vs. $-3.3 \mathrm{mmHg}, P<0.05$ ). Drinking $500 \mathrm{~mL}$ of water tended to increase stroke volume, cardiac output and vagal markers to a greater extent than $100 \mathrm{~mL}$.

Conclusions: Our data suggest that drinking a large volume $(500 \mathrm{~mL})$ of water before a meal may attenuate postprandial hypotension in older adults.
\end{abstract}

\section{Introduction}

An important consequence of ageing is the tendency for blood pressure to fall after eating a meal. Clinically, postprandial hypotension is defined as a reduction in blood pressure of $20 \mathrm{mmHg}$ within $2 \mathrm{~h}$ after having a meal [1] and about two-thirds of older adults admitted to geriatric departments were found to have postprandial hypotension [1]. The most common symptoms of postprandial hypotension are dizziness, nausea, weakness and

Abbreviations: SBP, systolic blood pressure; DBP, diastolic blood pressure; HR, heart rate; SV, stroke volume; $\mathrm{CO}$, cardiac output; TPR, total peripheral resistance; BRS, baroreflex sensitivity; HF_RRI, high-frequency component of heart rate variability.

* Corresponding author. Division of Physiology, Department of Medicine, University of Fribourg, Chemin du Musée 5, 1700 Fribourg, Switzerland. Tel.: +4126300 8675; fax: +4126300 9734 .

E-mail address: erikkonrad.grasser@unifr.ch (E.K. Grasser).

1 These authors contributed equally to the study. light-headedness [1] but more severe consequences such as syncope have also been reported. Meal composition appears to play a role in postprandial hypotension because carbohydrates, particularly glucose, have the greatest blood pressure lowering effect [2]. Even older adult individuals with no history or symptoms of postprandial hypotension tend to show some degree of blood pressure reduction after ingesting a carbohydrate meal [3].

Ingesting a meal causes pooling of blood in the abdominal vasculature that is accompanied by a drop in systemic peripheral resistance, activation of the sympathetic nervous system and increases in heart rate and cardiac output (CO) [4,5], but the rise in $\mathrm{CO}$ is not sufficient to counteract the dropping blood pressure, which could lead to presyncopal symptoms or even syncope. Drinking approximately $500 \mathrm{~mL}$ of water acutely increased blood pressure in autonomic failure patients as well as in older subjects [6] and improved orthostatic tolerance in healthy humans [7]. Moreover, in patients suffering from primary autonomic failure, ingestion of $480 \mathrm{~mL}$ of tap water in combination with a meal markedly improved the postprandial drop in blood pressure [8]. However, to 
date, the precise mechanisms of postprandial hypotension are not well characterized, though inadequate autonomic nervous system responses to meal ingestion have been implicated [1].

In the study reported here, we investigated the effects of tap water in combination with a breakfast meal on cardiovascular parameters and cardiac vagal tone in older adults. We chose a light meal because older adults often consume small meals of about $400 \mathrm{kcal}$ [9]. Furthermore, a breakfast meal is the least likely meal to be skipped by older adults [9]. Therefore, we evaluated beat-tobeat hemodynamic parameters and autonomic responses in a group of older individuals drinking either $100 \mathrm{ml}$ or $500 \mathrm{ml}$ before a light breakfast meal. The responses were compared to a control group comprised of young and healthy adults. It was hypothesized that ingestion of a higher amount of water would prevent the postprandial drop in blood pressure in older and generally healthy individuals.

\section{Methods}

\subsection{Participants}

Eleven young (four females; Age: $25 \pm 1$ years; Height: $171 \pm 3 \mathrm{~cm}$; Weight: $75 \pm 3 \mathrm{~kg}$; Body Mass Index: $25.8 \pm 0.8 \mathrm{~kg} \mathrm{~m}^{-2}$ ) and twelve older (five females; Age: $67 \pm 1$ years; Height: $167 \pm 2 \mathrm{~cm}$; Weight: $75 \pm 2 \mathrm{~kg}$; Body Mass Index: $27.0 \pm 0.8 \mathrm{~kg} \mathrm{~m}^{-2}$ ) non-smoking individuals were recruited. The participants in the young control group were recruited from local students and their friends, whilst older adults were recruited from relatives and friends of our local staff. Seven of the older subjects were normotensive, whilst five were taking medication for hypertension ( $\beta 1$ selective beta blockers $(n=2)$, angiotensin II receptor antagonists $(n=2)$ and a calcium-antagonist $(n=1)$. The participants were requested to avoid alcohol and caffeine for $24 \mathrm{~h}$ and were studied in the morning starting at 8am after an overnight (12h) fast. The treated hypertensive subjects refrained from taking their medication on the morning of the study. Written informed consent was obtained from each participant and the study protocol received local ethics committee approval in accordance with the Declaration of Helsinki.

\subsection{Study design}

All measurements were performed between 08.00 and $09.00 \mathrm{~h}$ in a temperature-controlled $\left(22 \pm 1^{\circ} \mathrm{C}\right)$ quiet laboratory with the study participants seated in a comfortable armchair. Every older adult attended two separate experimental sessions, with each session ( $100 \mathrm{~mL}$ or $500 \mathrm{~mL}$ tap water before a meal) separated by at least two days according to a crossover study design; the young group served as a control for the condition with $100 \mathrm{~mL}$ before the meal. On arrival at the laboratory, subjects were asked to empty their bladders if necessary and to sit in a comfortable armchair. Subjects clothing consisted of a t-shirt, trousers and shoes. The equipment for cardiovascular monitoring was then attached.

Following a period for cardiovascular stability (20-30 min), a baseline recording was then made for $20 \mathrm{~min}$. Then, the older adults ingested over four minutes either $100 \mathrm{~mL}$ or $500 \mathrm{~mL}$ of tap water at room temperature (the control group drank $100 \mathrm{~mL}$ water) which was followed by the consumption of the test meal over a period of $15 \mathrm{~min}$ and cardiovascular recordings were resumed for 90 min after the meal. The meal comprised a light breakfast of $100 \mathrm{~g}$ of toast-bread, over which was spread $12 \mathrm{~g}$ of butter and $30 \mathrm{~g}$ of jam. The total energy content was $1708 \mathrm{~kJ}$, with carbohydrate, fat and protein respectively contributing to $60 \%, 31 \%$ and $9 \%$ of the energy intake. Such small meals are often consumed by older adults [9].

\subsection{Cardiovascular recordings}

Cardiovascular recordings were performed using a Task Force Monitor (TFM) (CNSystems, Medizintechnik, Graz, Austria) with data sampled at a rate of $1.000 \mathrm{~Hz}$ [10]. Continuous blood pressure was monitored using the Penaz principle from either the index or middle finger of the right hand and was calibrated to oscillometric brachial blood pressure measurements on the contralateral arm. Impedance cardiography measurements were performed using an improved estimate of thoracic volume [11], which allows calculation of stroke volume (SV). Electrode strips were placed at the neck and thoracic regions, the latter specifically at the midclavicular at the xiphoid process level (CNSystems standard electrode kits).

\subsection{Autonomic measurements}

High frequency (HF: $0.17-0.40 \mathrm{~Hz}$ ) power components of RRintervals (HF_RRI) were evaluated and given in absolute values $\left(\mathrm{ms}^{2}\right)$. We used changes in the HF range of heart rate variability to assess parasympathetic activity because HF_RRI is primarily mediated by parasympathetic nerve modulation $[12,13]$. Powers of HF_RRI were analyzed after natural logarithmic transformation. Baroreflex sensitivity (BRS) was determined from spontaneous fluctuations in blood pressure and cardiac interval using the sequence technique [14].

\subsection{Data and statistical analysis}

Values of cardiac interval, systolic blood pressure ((SBP), mean blood pressure and diastolic blood pressure (DBP)), SV and autonomic variables were averaged every 10 min during the baseline period and every 15 min during the 90 min post-drink period. CO was calculated as the product of SV and heart rate (HR), where HR was calculated from the appropriate cardiac interval. Total peripheral resistance (TPR) was calculated as mean blood pressure (MBP) divided by CO, where MBP was calculated as the result of $\mathrm{DBP}+1 / 3$ (SBP-DBP). Baseline values and responses to the intervention were statistically not different between the treated hypertensive and the normotensive group and were, therefore, combined for the final analysis.

Blood pressure variables started to decline significantly below baseline values around $30 \mathrm{~min}$ postprandial in older adults, therefore we chose the period from 30 to 90 min postprandial as appropriate for a statistical discrimination between the drink volumes used (Figs. 1-3, right panel).

Statistical analyses were performed using GraphPad Prism (Version 5, San Diego, CA, USA). All values are reported as means \pm SE. Repeated-measures ANOVA with Dunnetts post hoc testing were used to test for changes over time from baseline values. One-way ANOVA with Newman-Keuls post hoc testing was used to compare baseline values between the three groups. A paired $t$-test was used to compare mean changes of the 30-90 min post-drink period with baseline values and between the conditions. All reported $P$ values are two-sided. For all tests, significance was set at $P<0.05$.

\section{Results}

Baseline resting values were similar for hemodynamic and autonomic measurement parameters in older adults between the drinks. Baseline DBP and TPR were higher and SV, BRS and HF_RRI lower in the respective older adult group compared to the younger controls (Table 1). None of the test subjects showed unpleasant effects after ingesting the test meal regardless of the corresponding drink type. We could not find statistical differences related to blood 

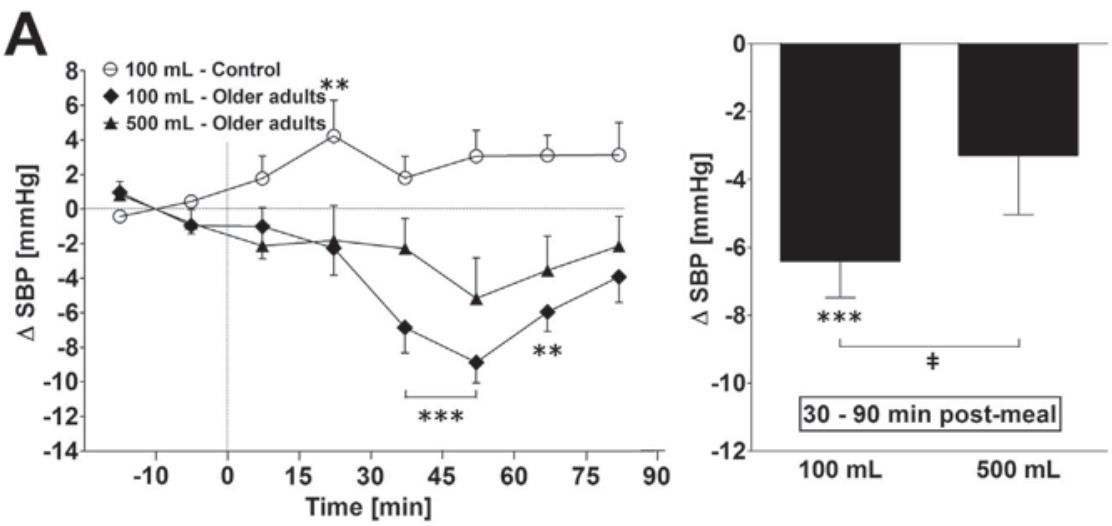

\section{B}
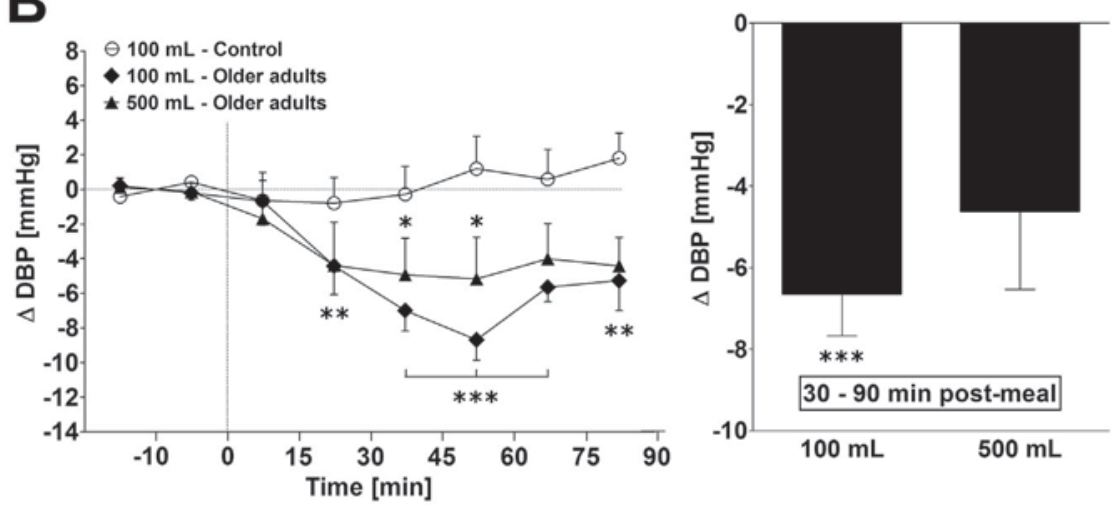

C
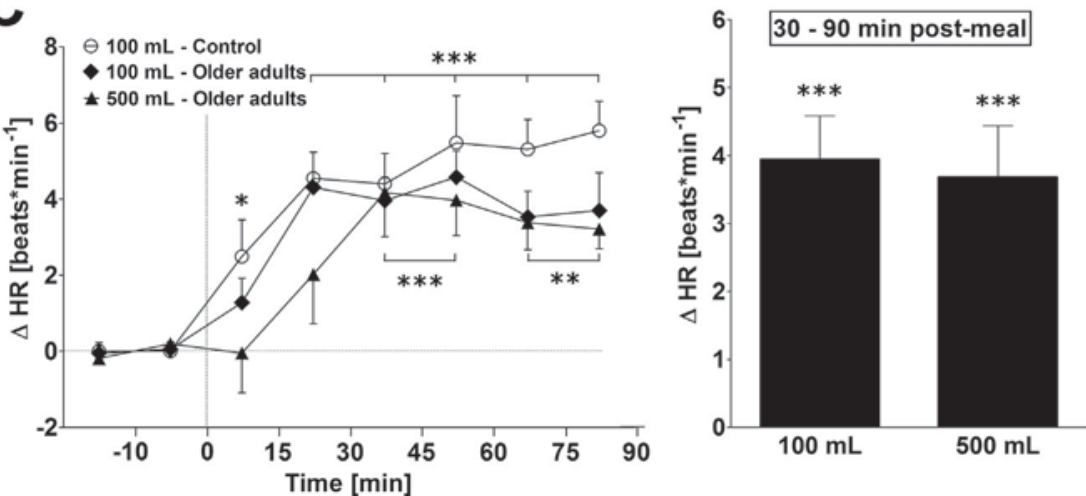

Fig. 1. Left panel: Time course of the changes of systolic blood pressure (SBP) (A), diastolic blood pressure (DBP) (B) and heart rate (HR) (C) in young controls (open circle $\bigcirc$ ) and older adults drinking either $100 \mathrm{~mL}$ (closed rhomb $\bullet$ ) or $500 \mathrm{~mL}$ (closed triangle $\boldsymbol{\Delta}$ ) water preceding a meal. Right panel: Mean responses in older adults averaged from 30 to 90 min postprandial relative to baseline values and presented as a delta (i.e. average from 30 to 90 min postprandial, minus the average over the 20 min baseline period). Time 0 indicates 15 min after ingestion of meal and drinks. ${ }^{*} P<0.05,{ }^{* *} P<0.01$ and ${ }^{* * *} P<0.005$ statistically significant differences over time from baseline values (left and right panel). ${ }^{\ddagger} P<0.05$, statistically significant difference between responses to the drinks (right panel).

pressure variables - or to other observed variables (data not shown) - between the hypertension-treated and the untreated healthy older adults (Table 2).

\subsection{Hemodynamic changes}

Figure 1 shows changes for SBP, DBP and HR in response to ingestion of $100 \mathrm{~mL}$ of tap water before a meal in young and older adult humans, and also in the same older adults ingesting $500 \mathrm{~mL}$ tap water. In older adults, ingestion of $100 \mathrm{~mL}$ or $500 \mathrm{~mL}$ water before a breakfast meal led to decreased blood pressure variables below baseline levels around $30 \mathrm{~min}$ postprandial with the lowest values around $60 \mathrm{~min}(\mathrm{SBP} 100 \mathrm{~mL}$ : $-8.9 \mathrm{mmHg}$; SBP
$500 \mathrm{~mL}:-5.2 \mathrm{mmHg}$; DBP $100 \mathrm{~mL}:-8.7 \mathrm{mmHg}$; DBP $500 \mathrm{~mL}:-5.2 \mathrm{mmHg}$ ) but not in younger controls. A comparison of mean responses between the two drink conditions between 30 and 90 min postprandial revealed a more pronounced drop for SBP when ingesting the lower volume (SBP: $-6.4 \mathrm{vs}-3.3 \mathrm{mmHg}$, $P<0.05$ ), whilst the drop in DBP was not significantly different between the drinks (DBP: $-6.7 \pm$ vs $-4.2 \mathrm{mmHg}, P=0.32$ ). A comparison of mean responses in all drink groups over the $90 \mathrm{~min}$ study period found SBP as significantly higher in the young controls than in older adults $(P<0.05)$, whilst DBP was found different comparing young controls with older adults ingesting $100 \mathrm{~mL}$ $(P<0.05)$ but not $500 \mathrm{~mL}$. In older adults, drinking $100 \mathrm{~mL}$ of water before the meal started to increase HR soon after ingestion with the 

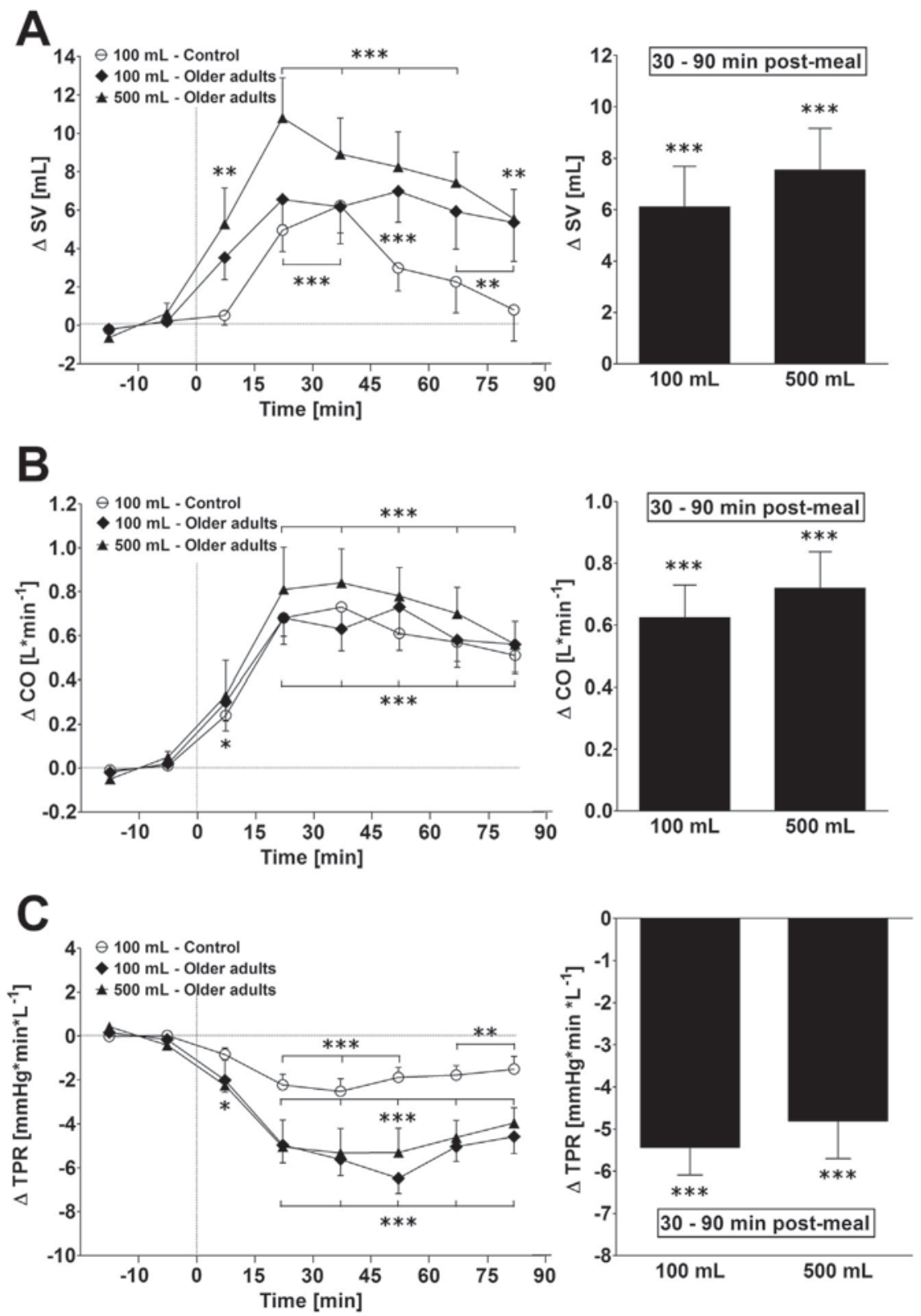

Fig. 2. Left panel: Time course of the changes of stroke volume (SV) (A), cardiac output (CO) (B) and total peripheral resistance (TPR) (C) in young controls (open circle $\bigcirc$ ) and older adults drinking either $100 \mathrm{~mL}$ (closed rhomb $\bullet$ ) or $500 \mathrm{~mL}$ (closed triangle $\boldsymbol{\Delta}$ ) water preceding a meal. Right panel: Mean responses in older adults averaged from 30 to $90 \mathrm{~min}$ postprandial relative to baseline values and presented as a delta (i.e. average from 30 to 90 min postprandial, minus the average over the 20 min baseline period). Time 0 indicates 15 min after ingestion of meal and drinks. ${ }^{*} P<0.05,{ }^{* *} P<0.01$ and ${ }^{* * *} P<0.005$ statistically significant differences over time from baseline values (left and right panel).

highest values around $60 \mathrm{~min}\left(+4.6\right.$ beats $\left.\mathrm{min}^{-1}\right)$. The $500 \mathrm{~mL}$ condition showed a latency in the rise of HR but rose to similar levels as with $100 \mathrm{~mL}$.

Figure 2 shows changes for SV, CO and TPR in response to ingestion of $100 \mathrm{~mL}$ of tap water before a meal in young and older adult humans, and also in the same older adults ingesting $500 \mathrm{~mL}$ tap water. Water ingestion $(500 \mathrm{~mL})$ before a breakfast meal increased SV soon over baseline values with a maximum around $30 \mathrm{~min}(+10.8 \mathrm{~mL})$, whilst drinking $100 \mathrm{~mL}$ water before a breakfast meal increased SV more gradually with the highest value around $60 \mathrm{~min}(+7.0 \mathrm{~mL})$. SV increased to a larger extent in older adults ingesting $500 \mathrm{~mL}$ compared to the young control group $(P<0.05)$, whilst no difference between the older adults drink conditions could be observed. CO showed a similar time course in all groups, with a trend for a higher CO with the higher volume (Fig. 2). TPR dropped to a larger extent in older adults compared to the young control group ( $P<0.05$, respectively), whilst no difference between the older adults drink conditions could be observed.

\subsection{Autonomic changes}

Figure 3 shows changes for BRS and HF_RRI in response to ingestion of $100 \mathrm{~mL}$ of tap water before a meal in young and older adult humans, and also in the same older adults ingesting $500 \mathrm{~mL}$ tap water. Water ingestion $(500 \mathrm{~mL})$ before a breakfast meal tended to increase BRS slightly over baseline levels, but drinking $100 \mathrm{~mL}$ before the breakfast meal significantly decreased BRS in older adults as well as in the younger controls $(-0.83$ and $-2.6 \mathrm{~ms} \mathrm{mmHg}^{-1}$, respectively). The time course for HF_RRI showed an early peak value $\left(0.66 \mathrm{ln} \mathrm{ms}^{2}\right)$ shortly after ingestion 
A
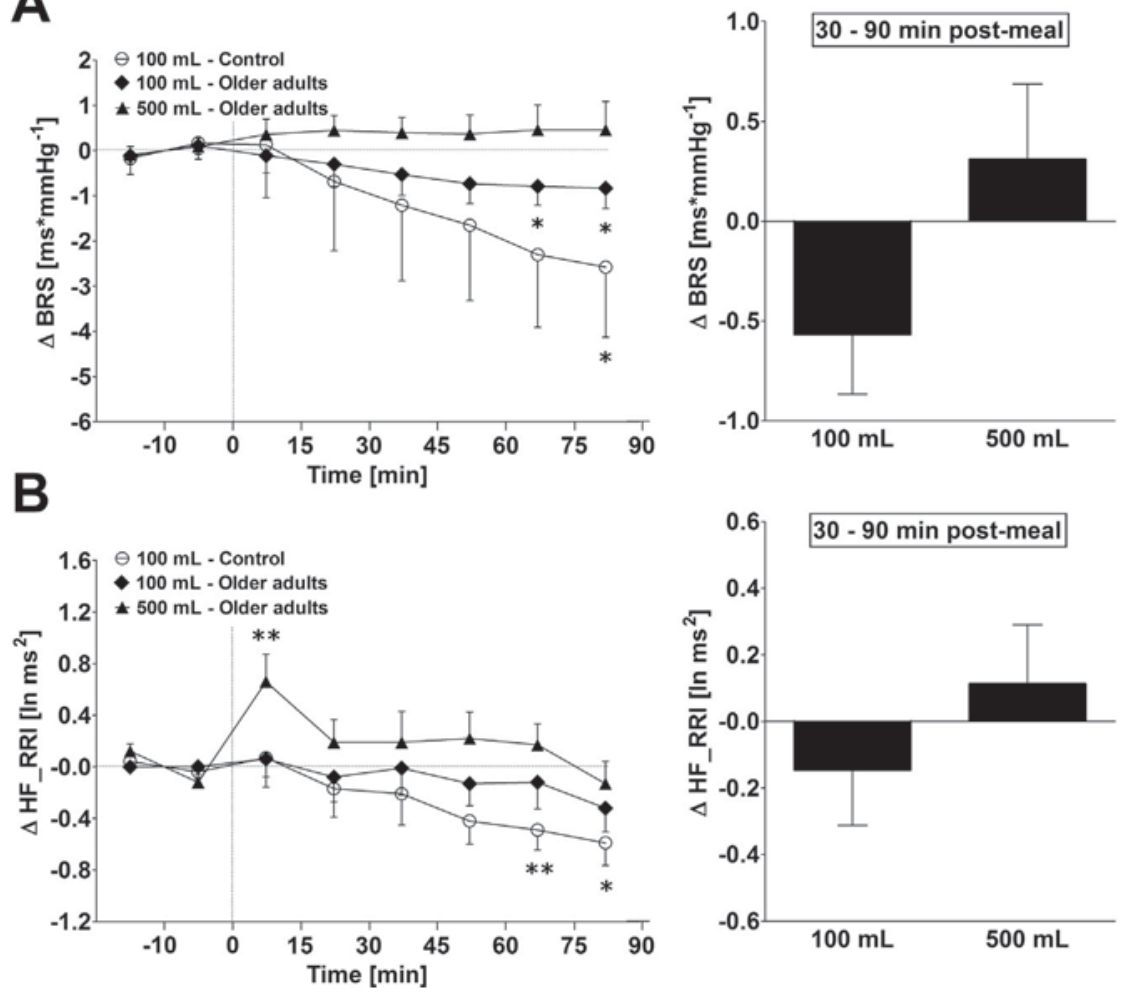

Fig. 3. Left panel: Time course of the changes of baroreflex sensitivity (BRS) (A) and high-frequency power of RR-Interval (HF_RRI) (B) in young controls (open circle $O$ ) and older adults drinking either $100 \mathrm{~mL}$ (closed rhomb $\bullet$ ) or $500 \mathrm{~mL}$ (closed triangle $\boldsymbol{\Delta}$ ) water preceding a meal. Right panel: Mean responses in older adults averaged from 30 to 90 min postprandial relative to baseline values and presented as a delta (i.e. average from 30 to 90 min postprandial, minus the average over the 20 min baseline period). Time 0 indicates 15 min after ingestion of meal and drinks. ${ }^{*} P<0.05,{ }^{* *} P<0.01$ and ${ }^{* * *} P<0.005$ statistically significant differences over time from baseline values (left and right panel).

$500 \mathrm{~mL}$ water and then quickly returned towards baseline values, whilst ingestion of $100 \mathrm{~mL}$ (in older adults less pronounced than in the younger controls) resulted in a slow progressive decrease. A comparison between mean responses over the 90 min post-drink period observed a tendency for HF_RRI to increase after ingestion of $500 \mathrm{~mL}$ compared with $100 \mathrm{~mL}$ water in older adults $(+0.22$ vs. $\left.-0.10 \ln \mathrm{ms}^{2}, P=0.07\right)$.

\section{Discussion}

To our knowledge, this is the first study where the hemodynamic and autonomic responses of water ingestion before a meal were investigated in older adults under controlled conditions in a crossover study design. We assessed blood pressure variables by continuous beat-to-beat cardiovascular measurements and observed (i) a postprandial reduction in SBP and DBP in older adults drinking $100 \mathrm{~mL}$ before the meal, which was not seen in a younger control group and (ii) an attenuation of postprandial hypotension, significant for SBP and a trend for DBP, when drinking a much larger drink volume of water. Thus, our results suggest that the amount of water drunk before a meal significantly influences postprandial blood pressure in older adults.

The postprandial blood pressure decrease in our older subjects is considered a normal response in older adults [3,15] and, although this blood pressure drop may have serious clinical consequences, effective countermeasures are still elusive. The physiological responses to water ingestion in humans have considerable impact on hemodynamics. In patients suffering from severe autonomic failure, drinking water increased blood pressure substantially $[6,16]$ accompanied by a rise of plasma norepinephrine [6]. However, the pressure response due to ingestion of similar amounts of water is not seen in young and healthy subjects $[6,17,18]$ despite an augmented muscle sympathetic nerve activity and a rise in plasma norepinephrine levels [18]. In our study, a standard light meal $(1708 \mathrm{~kJ})$, which was preceded by ingestion of $100 \mathrm{~mL}$ water, produced significant decreases in beat-to-beat measured SBP and DBP variables starting around 30 min postprandial in older adults but was not seen in a younger control group. Ingesting $500 \mathrm{~mL}$ of water before the meal significantly reduced the postprandial drop in SBP whilst DBP showed a trend towards an attenuation of the postprandial pressure drop. Therefore, it is conceivable that the amount of water ingested before a meal influences positively the postprandial SBP in older adults. In agreement with our results, a previous study observed no significant changes in SBP compared to baseline levels but a small drop in DBP after a breakfast meal plus water ingestion $(350 \mathrm{~mL}$ ) at a comparable composition (63\% carbohydrates, $27 \%$ fat and $10 \%$ proteins) and energy content (1301 kJ) [19]. Our observation of a water-induced attenuation of the postprandial decrease in blood pressure is further supported by a study where gastric distension raised volume dependent blood pressure variables during intraduodenal glucose infusion [20]. Taken together, in response to the higher water drink volume, we observed an attenuation of the decrease in SBP by $3.1 \mathrm{mmHg}$ compared to the lower drink volume. Whether this blunting is of clinical relevance remains to be determined in patients presenting symptoms of postprandial hypotension.

In the present study, we observed that postprandial SV and CO increased in response to water ingestion before a meal both in young controls and in older adults, with the latter's response being greater, particularly with the large water volume. TPR decreased in response to the meal, independently of the amount of water. The decrease in TPR was found to be more prominent in older adults 
Table 1

Baseline data recorded $20 \mathrm{~min}$ before ingesting either $100 \mathrm{~mL}$ or $500 \mathrm{~mL}$ of tap water which was followed by consumption of a standard light meal $(1708 \mathrm{~kJ})$ in older adults and young controls drinking $100 \mathrm{~mL}$.

\begin{tabular}{|c|c|c|c|}
\hline & $\begin{array}{l}\text { Controls } \\
100 \mathrm{~mL}\end{array}$ & $\begin{array}{l}\text { Older adults } \\
100 \mathrm{~mL}\end{array}$ & Older adults $500 \mathrm{~mL}$ \\
\hline Systolic blood pressure, $\mathrm{mmHg}$ & $112 \pm 2$ & $120 \pm 3$ & $119 \pm 4$ \\
\hline Diastolic blood pressure, $\mathrm{mmHg}$ & $72 \pm 2$ & $83 \pm 2^{*}$ & $81 \pm 3^{*}$ \\
\hline Heart rate, beats $\min ^{-1}$ & $61 \pm 3$ & $62 \pm 2$ & $62 \pm 2$ \\
\hline Stroke volume, mL & $78 \pm 3$ & $60 \pm 2 \dagger$ & $61 \pm 3 \dagger$ \\
\hline Cardiac output, $\mathrm{L} \min ^{-1}$ & $4.7 \pm 0.1$ & $3.7 \pm 0.2 \dagger$ & $3.7 \pm 0.2 \dagger$ \\
\hline $\begin{array}{l}\text { Total peripheral resistance, } \\
\mathrm{mmHg} \mathrm{L}^{-1} \mathrm{~min}\end{array}$ & $18.4 \pm 0.8$ & $26.5 \pm 1.4 \dagger$ & $25.6 \pm 1.7 \dagger$ \\
\hline Baroreflex sensitivity, $\mathrm{ms} \mathrm{mmHg}^{-1}$ & $26.2 \pm 3.6$ & $10.3 \pm 1.2 \dagger$ & $9.0 \pm 0.6 \dagger$ \\
\hline High frequency power of RRI, ms ${ }^{2}$ & $1057 \pm 233$ & $188 \pm 62 \dagger$ & $159 \pm 44 \dagger$ \\
\hline
\end{tabular}

RRI, RR-interval; *, $p<0.05$ compared to controls; $\uparrow, p<0.005$ compared to young controls using one-way ANOVA with Newman-Keuls multiple comparison post-hoc testing. Data are presented as means $\pm \mathrm{SE}$.

Table 2

Baseline and mean cardiovascular data averaged from 30 to 90 min postprandial relative to baseline values and presented as a delta $(\Delta)$ (i.e. average from 30 to $90 \mathrm{~min}$ postprandial, minus the average over the $20 \mathrm{~min}$ baseline period).

\begin{tabular}{rllll}
\hline & $\begin{array}{l}\text { Hypertensives } \\
\text { baseline }\end{array}$ & $\begin{array}{l}\text { Normotensives } \\
\text { baseline }\end{array}$ & $\begin{array}{l}\text { Hypertensives } \\
\text { Normotensives } \\
\Delta\end{array}$ \\
\hline $\begin{array}{rlll}\text { SBP, } \mathrm{mmHg} \\
(100 \mathrm{~mL})\end{array}$ & $124 \pm 6$ & $118 \pm 3$ & $-7.2 \pm 1.2$ & $-5.8 \pm 1.7$ \\
$\begin{array}{r}\mathrm{DBP}, \mathrm{mmHg} \\
(100 \mathrm{~mL})\end{array}$ & $85 \pm 5$ & $81 \pm 1$ & $-7.9 \pm 1.4$ & $-5.8 \pm 1.5$ \\
$\begin{array}{r}\mathrm{SBP}, \mathrm{mmHg} \\
(500 \mathrm{~mL})\end{array}$ & $124 \pm 8$ & $115 \pm 5$ & $-4.4 \pm 2.5$ & $-2.5 \pm 2.6$ \\
$\begin{aligned} \mathrm{DBP}, \mathrm{mmHg} \\
(500 \mathrm{~mL})\end{aligned}$ & $85 \pm 6$ & $77 \pm 3$ & $-6.1 \pm 3.3$ & $-3.6 \pm 2.4$ \\
& & & &
\end{tabular}

SBP: Systolic blood pressure; DBP: Diastolic blood pressure; Hypertensives refer to treated hypertensive subjects; Normotensives refer to normotensive subjects. $100 \mathrm{~mL}$ and $500 \mathrm{~mL}$ refer to the amount of water before the breakfast meal. An unpaired $t$-test was used to compare postprandial cardiovascular changes between normotensive $(n=7)$ and hypertensive $(n=5)$ older adults. No significant changes have been found. Data are presented as means \pm SE and statistical significance was set at $P<0.05$.

compared to the younger control group. Our observation of an increase in SV, CO and a decrease in TPR in response to the meal could be due to the action of insulin. Using a hyperinsulinemic euglycemic study design, Baron and Brechtel investigated the actions of insulin and found that systemic vascular resistance decreased dosedependently in normal weight humans, with a corresponding increase in CO with an elevation of both SV and HR [21]. We observed for HR a graded response with significant increases over time in response to the meal but no significant influence of the drink volume, thereby confirming previous observations [5,19].

Ingestion of water is known to increase the parasympathetic tone with changes in HF_RRI and BRS in healthy humans leading to significant HR reductions starting early after ingestion and maintaining for approximately 30 min post-drink $[17,22]$. On the other hand, it was observed that a liquid mixed-meal (1675 kJ) did not affect postprandial high-frequency spectral power in healthy older humans ( 80 years) but increased HR [5]. In line with these findings, we could not find a significant influence of the meal with a lower drink volume on HF_RRI and BRS but a trend towards increased levels in response to a higher drink volume.

In the present study, we included not only healthy normotensive older adult individuals but also some older adult subjects that were treated for hypertension. We could not find statistical significant differences in our investigated variables between the hypertensiontreated and the untreated older adults, therefore we combined both groups to increase statistical power (Table 2).

\section{Conclusions}

The present study evaluated beat-to-beat hemodynamic parameters and autonomic responses in a group of older individuals ingesting either $100 \mathrm{~mL}$ or $500 \mathrm{~mL}$ before a meal and in a young control group ingesting $100 \mathrm{~mL}$. Our data suggest that drinking a larger volume of water before a meal attenuates the postprandial decrease in blood pressure in older adults.

\section{Conflict of interest}

The study authors declare no conflict of interests.

\section{Sources of funding}

Research related to this paper was supported in part by a grant from the Swiss National Science Foundation [Project number 122554 to JPM].

\section{Contributions of the authors}

JPM and AGD designed research; BG and GY conducted research and recruited subjects; EKG analyzed the data and wrote the first draft of the manuscript; All authors contributed towards, read and approved the final manuscript.

\section{References}

[1] Jansen R, Lipsitz LA. Postprandial hypotension - epidemology, pathophysiology, and clinical management. Ann Intern Med 1995;122:286-95.

[2] Potter JF, Heseltine D, Hartley G, Matthews J, MacDonald IA, James OF. Effects of meal composition on the postprandial blood pressure, catecholamine and insulin changes in elderly subjects. Clin Sci 1989;77:265-72.

[3] Lipsitz LA, Fullerton KJ. Postprandial blood pressure reduction in healthy elderly. J Am Geriatr Soc 1986;34:267-70.

[4] Heseltine D, Potter JF, Hartley G, Macdonald IA, James OF. Blood pressure, heart rate and neuroendocrine responses to a high carbohydrate and a high fat meal in healthy young subjects. Clin Sci 1990;79:517-22.

[5] Lipsitz LA, Ryan SM, Parker JA, Freeman R, Wei JY, Goldberger AL. Hemodynamic and autonomic nervous system responses to mixed meal ingestion in healthy young and old subjects and dysautonomic patients with postprandial hypotension. Circulation 1993;87:391-400.

[6] Jordan J, Shannon JR, Black BK, Ali Y, Farley M, Costa F, et al. The pressor response to water drinking in humans: a sympathetic reflex? Circulation 2000;101:504-9.

[7] Schroeder C, Bush VE, Norcliffe LJ, Luft FC, Tank J, Jordan J, et al. Water drinking acutely improves orthostatic tolerance in healthy subjects. Circulation 2002:106:2806-11.

[8] Shannon JR, Diedrich A, Biaggioni I, Tank J, Robertson RM, Robertson D, et al. Water drinking as a treatment for orthostatic syndromes. Am J Med 2002;112: 355-60.

[9] Locher JL, Robinson CO, Roth DL, Ritchie CS, Burgio KL. The effect of the presence of others on caloric intake in homebound older adults. J Gerontol A Biol Sci Med Sci 2005;60:1475-8.

[10] Girona M, Grasser EK, Dulloo AG, Montani JP. Cardiovascular and metabolic responses to tap water ingestion in young humans: does the water temperature matter? Acta Physiol (Oxf) 2014;211:358-70.

[11] Fortin J, Habenbacher W, Heller A, Hacker A, Gruellenberger R, Innerhofer J et al. Non-invasive beat-to-beat cardiac output monitoring by an improved method of transthoracic bioimpedance measurement. Comput Biol Med 2006;36:1185-203.

[12] Stauss HM. Heart rate variability. Am J Physiol Regul Integr Comp Physiol 2003;285:R927-31.

[13] Camm AJ, Malik M, Bigger JT, Breithardt G, Cerutti S, Cohen RJ, et al. Heart rate variability - standards of measurement, physiological interpretation, and clinical use. Circulation 1996;93:1043-65.

[14] Bertinieri G, Dirienzo M, Cavallazzi A, Ferrari AU, Pedotti A, Mancia G. A new approach to analysis of the arterial baroreflex. J Hypertens 1985;3:S79-81.

[15] Bellomo G, Santucci S, Aisa G, Parnetti L. Meal-induced arterial blood pressure variations in the elderly. Gerontology 1988;34:311-4.

[16] Cariga P, Mathias CJ. Haemodynamics of the pressor effect of oral water in human sympathetic denervation due to autonomic failure. Clin Sci 2001:101: 313-9.

[17] Brown CM, Barberini L, Dulloo AG, Montani JP. Cardiovascular responses to water drinking: does osmolality play a role? Am J Physiol Regul Integr Comp Physiol 2005;289:R1687-92. 
[18] Scott EM, Greenwood JP, Gilbey SG, Stoker JB, Mary DA. Water ingestion increases sympathetic vasoconstrictor discharge in normal human subjects. Clin Sci 2001;100:335-42.

[19] Ahuja KD, Robertson IK, Ball MJ. Acute effects of food on postprandial blood pressure and measures of arterial stiffness in healthy humans. Am J Clin Nutr 2009;90:298-303.

[20] Vanis L, Gentilcore D, Lange K, Gilja OH, Rigda RS, Trahair LG, et al. Effects of variations in intragastric volume on blood pressure and splanchnic blood flow during intraduodenal glucose infusion in healthy older subjects. Am J Physiol Regul Integr Comp Physiol 2012;302:R391-9.

[21] Baron AD, Brechtel G. Insulin differentially regulates systemic and skeletal muscle vascular resistance. Am J Physiol 1993;265:E61-7.

[22] Routledge HC, Chowdhary S, Coote JH, Townend JN. Cardiac vagal response to water ingestion in normal human subjects. Clin Sci 2002;103:157-62. 